\title{
The current state of respiratory research in the UK
}

\author{
Noel Snell, ${ }^{1}$ Ian Jarrold, ${ }^{1}$ Stephen Holgate ${ }^{2}$
}

In 1985, Malcolm (now Sir Malcolm) Green wrote a Thorax editorial bemoaning the lack of funding for research into respiratory diseases in the UK and announcing the launch of a new charity devoted to raising funds specifically for respiratory researchthe British Lung Foundation (BLF). ${ }^{1}$ Subsequent reviews from the BLF and other perspectives reaffirmed the theme of relative underfunding for research in respiratory disorders compared with other disease areas with a comparable disease burden. ${ }^{2-4}$ As the BLF celebrates its 30th anniversary this year, it seems an appropriate time to take stock of the current situation.

Figure 1 is derived from data generated by the UK Clinical Research Collaboration. ${ }^{5}$ It shows very clearly the marked disparity in research spending on respiratory disorders compared with other comparable disease areas, both in absolute terms and also, more tellingly, in relation to disease burden as measured by WHO disability-adjusted lifeyear rates in the UK. There is little real change in the relative spends between 2004-2005 and 2009-2010. A third report is due to be published later this year; we await the updated figures with interest.

We have attempted to obtain figures for recent spending on UK respiratory research by government agencies (the Medical Research Council, MRC; and National Institute for Health Research, NIHR) and relevant major charities (see table 1). The annual research spend by each body is the most recent full-year figure obtainable from publicly-available annual reports (financial years and reporting periods differ between the various bodies; hence, the period covered lies between 2012 and 2015).

It can be seen that about two-thirds of UK respiratory research funding is provided by the MRC, Wellcome Trust, NIHR and Cancer Research UK (CRUK), but it should be noted that respiratory research accounts for only $2.5 \%-4.5 \%$ of total research spending by these bodies. The total annual spend by government

\footnotetext{
${ }^{1}$ Research Department, British Lung Foundation, London, UK; ${ }^{2}$ Faculty of Medicine Clinical and Experimental Sciences, Southampton General Hospital, Southampton, UK
}

Correspondence to Dr Noel Snell, Research Department, British Lung Foundation, 73-75 Goswell Road, London EC1V 7ER, UK; noel.snell@blf.org.uk agencies and national charities on respiratory research in the period reviewed was approximately $£ 96$ million. To put this amount into context, it should be appreciated that the amount spent on cardiovascular research in 2013-2014 by a single charity alone (the British Heart Foundation) was $£ 115$ million.

Note that the figures in table 1 do not include funding from local hospital charities (which can be fairly substantial: eg, the Great Ormond Street Hospital Charity spent $£ 185000$ on respiratory research in 2013-2014) and NHS Trusts, although there is no reason to expect relative disease area funding by these bodies to differ significantly from other funding agencies. More importantly, the figures exclude research funding by the pharmaceutical industry (see later).

The BLF recently commissioned a report on the epidemiology of lung disease in the UK (the 'Respiratory Health of the Nation'), which is being launched at a meeting at the House of Commons in July 2015. This report shows that respiratory disease is currently (2012) the third most common cause of death in the UK (20\% of all deaths) behind nonrespiratory cancers $(23 \%)$ and cardiovascular disease (28\%), emphasising again the huge disparity between funding for respiratory research and other disease areas of comparable impact.

There have been no recent published reviews of UK respiratory research funding, but there has been an analysis of investment in respiratory infectious disease research between 1997 and $2010 .^{6}$ This showed marked year-on-year variability in total funding, possibly related to reactive investment in emerging infections such as avian influenza and Severe Acute Respiratory Syndrome. It is notable that, overall, the great majority of funding was for preclinical studies.

Historically, the pharmaceutical industry has been a major funder of respiratory research in the UK where many of these companies had their origins. However, in recent years, many companies have cut back on their respiratory research portfolios, with associated reductions in staff (and expertise), and closure of dedicated research departments (eg, the Pfizer site in Sandwich, Kent; the Novartis site in
Horsham, Surrey; and the AstraZeneca site in Charnwood, Leicestershire). ${ }^{7}$ It should be noted that recently-approved respiratory medications have mainly been 'me-too' drugs (long-acting bronchodilators, inhaled steroids and combinations). Numerous development programmes for agents acting on innovative drug targets have been discontinued due to lack of efficacy or toxicity, or for commercial reasons. ${ }^{7}$

Why does respiratory disease get such a small share of research funding, when it is so common and so economically important? It is not that the UK respiratory research community is bad at identifying research priorities, ${ }^{8-10}$ nor that we are behind the rest of the world in performing and publishing research. ${ }^{11}$ It is sobering that when we at the BLF discuss funding for respiratory research with major research spenders, a frequent comment is that the UK respiratory community is poor at collaboration, unhelpful when refereeing colleagues' submissions for funding and fails to speak with one voice, and that this is in marked contrast to the behaviour of, for example, the cardiology or rheumatology communities who are much more supportive of one another. This problem was recognised in a Thorax editorial over a decade ago. ${ }^{12}$

So, where should we go from here? It would be helpful to have an overarching body that could speak for respiratory research in the UK. The UK Respiratory Research Collaborative, established in 2006, has attempted to perform such a role. The short-lived Respiratory Alliance was less successful. The British Thoracic Society is the major body representing respiratory medicine in this country, but has not directly funded research for nearly 20 years, although active in clinical audit and in establishing disease registries (it is notable that the comparable body in the USA, the American Thoracic Society, has its own Foundation that has awarded more than US\$11 million to early-career researchers since 2004). ${ }^{13}$ The British Association for Lung Research represents clinical and more particularly non-clinical researchers, but is a small organisation with limited funds. Major respiratory charities (BLF, Asthma UK, Cystic Fibrosis UK, Action for Pulmonary Fibrosis and thoracic cancer organisations such as the Roy Castle Lung Cancer Foundation, Mesothelioma UK and the Mick Knighton Mesothelioma Research Fund) already collaborate to varying degrees. In addition to closer collaboration between organisations, we clearly also need a more collegiate and supportive attitude 


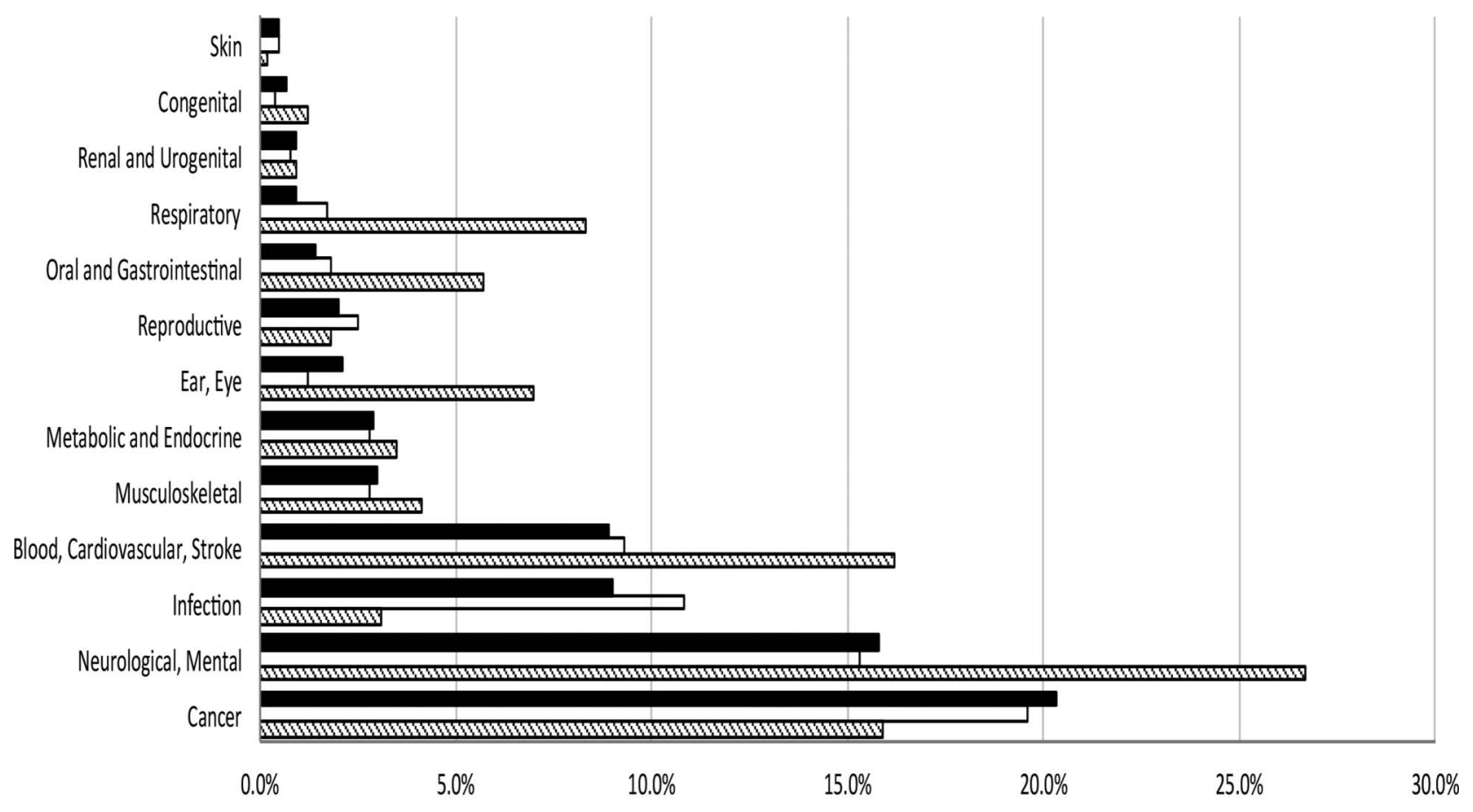

-2004-05 combined spend $\quad$ 2009-10 combined spend QWHO 2004 DALY data

Figure 1 Comparison of proportion of combined spend on health-specific categories with WHO DALY rates. Data taken from ref. 5, with permission. DALY, disability-adjusted life-year.

between individuals (perhaps it is time that external reviewers for grant applications should no longer be anonymous, a move made by many journals some years ago). ${ }^{14}$ The three highly successful NIHR-supported respiratory BRUs in England, and the inflammatory respiratory disease Translational Research Partnership, which brings together worldclass investigators in 26 of UK's leading academic and NHS research centres to support collaboration with the life sciences industry, are good examples of how the respiratory community can work together to strengthen translational science for patient benefit.

So is it all doom and gloom? There are some glimmers of hope. There has been a modest real increase in funding for respiratory research over the last few years; the BLF Board have resolved to implement year-on-year increases in research funding, CRUK have now made lung cancer one of their strategic priorities, TB is now one of Public Health England's priority areas and the NIHR have issued a highlight notice for mesothelioma research. AstraZeneca has reprioritised the respiratory therapeutic area, and research will be based at its new site

Table 1 Annual spend on respiratory research by major government agencies and charities

\begin{tabular}{|c|c|c|c|}
\hline Organisation & Amount & Year & Notes \\
\hline National Institute for Health Research & f24.9 million & 2012-2013 & $3.4 \%$ of total disease-specific research spend ( $₫ 732$ million) \\
\hline Medical Research Council & f21.1 million & 2013-2014 & $2.5 \%$ of total research spend ( $\mathrm{f} 845$ million) \\
\hline Wellcome Trust & f20.6 million & 2012-2013 & $2.8 \%$ of total charitable spend ( $\mathrm{f} 726$ million) \\
\hline Cancer Research UK & f16 million & 2013-2014 & Lung cancer: $4.5 \%$ of total research spend ( $\mathrm{n} 351$ million) \\
\hline Cystic Fibrosis Trust & f4.1 million & 2013-2014 & Spend on cystic fibrosis research \\
\hline Asthma UK & f2.9 million & 2012-2013 & Spend on asthma research \\
\hline NC3Rs & f1.8 million & 2014 & Research grants focusing solely on respiratory disease \\
\hline Medical Research Foundation & f1.6 million & 2014-2015 & Joint spend with Asthma UK \\
\hline Roy Castle Lung Cancer Foundation & f1.2 million & 2013 & Spend on lung cancer research \\
\hline British Lung Foundation & f1.1 million & 2012-2013 & All lung diseases \\
\hline Action Medical Research & £198 473 & 2015 & Primary ciliary dyskinesia research \\
\hline June Hancock Mesothelioma Research Fund & f170 891 & 2013-2014 & Spend on mesothelioma research \\
\hline Henry Smith Charity & f120000 & 2014 & CF (via Action Medical Research) \\
\hline British Medical Association & f110000 & 2014 & f60 000 asthma, $f 50000$ viral respiratory infection \\
\hline Chest, Heart \& Stroke Scotland & f59 965 & 2014 & Spend on asthma \\
\hline Northern Ireland Chest Heart \& Stroke & f18 974 & 2013 & Spend on research into RSV infection \\
\hline
\end{tabular}


in Cambridge. Looking more widely, over the last 3 years, the European Respiratory Society (ERS) has made increasing investments in supporting long-term and shortterm research fellowships, clinical research collaboratives, research seminars and task forces as well as the highly rated Lung Science Conference. The fellowship programme continues to increase on account of partnerships with national societies and industry. Based on the increasing need for greater coordination of research and 'interdisciplinary team science', the ERS is exploring the idea of a European Research Agency to develop greater opportunities for ERS members to put together competitive grant proposals in key areas, to develop disease registries and bioresources and to serve as a repository for pooling epidemiological, population, birth and disease cohorts and clinical trial data. Such an agency will also be in a strong position to work with industry as has proven so successful in such projects as the IMI U-BIOPRED (severe asthma) and PROACTIVE (COPD) as well as FP7 and Horizon 2020 programmes such as AirPROM (computational modelling), the EMBARC European Bronchiectasis Registry and EARIP (European Asthma Research and Innovation Partnership).
The success of these initiatives is absolutely dependent upon a joined-up approach across the research community in the UK and in Europe and beyond. Even in these times of financial stringency, if we can all pull together and speak with one voice, the future of respiratory research in the UK may look a little less bleak.

Competing interests None declared.

Provenance and peer review Commissioned; internally peer reviewed.

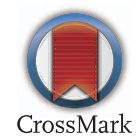

To cite Snell N, Jarrold I, Holgate S. Thorax 2015;70:1011-1013.

Published Online First 20 July 2015

Thorax 2015;70:1011-1013.

doi:10.1136/thoraxjnl-2015-207509

\section{REFERENCES}

1 Green M. Funding respiratory research. Thorax 1985:40:81-4

2 Green M. Thoracic medicine-research resources. Postgrad Med J 1988;64(Suppl 4):125-9.

3 MacNee W, Walden IM. Lung research funding in the UK: the British Lung Foundation perspective. Thorax 1998;53:239-40.
4 Holgate ST. The future of lung research in the UK. Thorax 2007:62:1028-32.

5 UK Health Research Analysis 2009/10 (UK Clinical Research Collaboration, 2012). http://www.ukcrc.org/ wp-content/uploads/2014/03/2UKHealthResearch Analysis-1.pdf (accessed 27 Jun 2015).

6 Head MG, Fitchett JR, Cooke MK, et al. Investments in respiratory infectious disease research 1997-2010: a systematic analysis of UK funding. BMJ Open 2014;4:e004600.

7 Snell NJC. Discontinued drug projects in the respiratory therapeutic area during 2012. Expert Opin Investig Drugs 2014;23:411-15.

8 Holgate ST, on behalf of the UK Respiratory Research Strategy Committee. Priorities for respiratory research in the UK. Thorax 2007;62:5-7.

9 Sheikh A, on behalf of the UKRRC Allergy and Respiratory Research Group. Developing consensus on national respiratory research priorities: key findings from the UK Respiratory Research Collaborative's e-Delphi exercise. Respir Med 2008;102:1089-92.

10 Pinnock H, Ostrem A, Rodriguez MR, et al. Prioritising the research needs of primary care: the International Primary Care Respiratory Group (IPCRG) e-Delphi exercise. Prim Care Respir J 2012;21:19-27.

11 Rippon I, Lewison G, Partridge MR. Research outputs in respiratory medicine. Thorax 2005:60:63-7.

12 Laurent GJ. Getting grant applications funded: lessons from the past and advice for the future. Thorax 2004;59:1010-1.

13 Donohue JF, Neumann L. The ATS foundation: 10 years old and powered to grow. Ann Amer Thorac Soc 2015;12:629-30.

14 Smith R. Opening up BMJ peer review. BMJ 1999;318:4 